Директор национального проекта «Сельские школы РФ» Махнев Н.А. заметил, что материалы встречи членов Совета Национального Союза селекционеров и семеноводов будут представлены участникам совещания по аграрным вопросам при Президенте РФ Путине В.В.

Профильное обучение уверенно вошло в школьную практику. Ученики уверенно защищают свои научно-исследовательские, социальные, практико-ориентированные проекты, успешно осваивают учебные программы, становятся победителями и призерами научно-практических конференций на региональном и всероссийском уровне. Пять выпускников 2021 года уже стали абитуриентами Уральского государственного аграрного университета на бюджетной основе.

Успешное настоящее в жизни школы 142 открывает дорогу в успешное будущее. Она «растет и развивается, и лучше нет судьбы».

$* * *$

1. Концепция профильного обучения (утверждена Приказом Министра образования № 2783 от 18.07 .2002 г.) // Школьные технологии. - 2002. — №4.

2. Приказ Минобразования РФ от 26.06. 2003 № 2757 «Об утверждении плана графика мероприятий по подготовке и введению профильного обучения на старшей ступени общего образования в условиях введения профильного обучения».

3. Рекомендации по организации профильного обучения на основе индивидуальных учебных планов обучающихся. Приложение к письму Департамента общего и дошкольного образования от 20.04.2004 № 14$51-102 / 13$.

4. О создании координационной группы Министерства образования и науки РФ по организации введения профильного обучения учащихся в общеобразовательных учреждениях, реализующих программы среднего (полного) общего образования. Приказ № 53 от 07. 09. 2004.

5. Артюхова И.С. Проблема выбора профиля обучения в старшей школе // Педагогика. - 2004. - №2. - С.28-33.

6. Гафурова Н.В. Разработка и реализация предпрофильного образования в рамках сетевой модели «ШколаВуз» // Школьные технологии. - 2004. - №5. - С.94-104.

7. Дзятковская Е.Н. Учет индивидуальных особенностей школьников при подготовке к профильному обучению// Профильная школа. - 2003. - №2. - С. 24-26.

8. Киселёва А.М. Эксперимент: совершенствование структуры и содержания общего образования. Профильное обучение / Под ред. д.и.н. А.М. Киселева. - М., 2001.

9. Новикова Т.Г. Теория и практика организации предпрофильной под готовки / Под ред. Т.Г. Новиковой. M., 2003.

\title{
Олейникова О.И. \\ Применение метода интегрированного чтения в обучении английскому языку студентов колледжа
}

ГБПОУ ВО «МПГК»

(Россия, Муром)

doi: 10.18411/trnio-09-2021-57

\section{Аннотация}

В статье рассматривается содержание метода интегрированного чтения в обучении английскому языку: критерии выбора текстов, разновидности сопутствующих упражнений на отработку лексики, грамматики и задействование различных видов учебной активности чтение, аудитория, письма и говорения. Отражена специфика обучения чтению студентов колледжа - различия в исходном уровне владения английским языком и необходимость дифференцированного подхода к выполнению комплекса упражнений на занятиях интегрированного чтения.

Ключевые слова: английский язык, интегрированное чтение, интерактивные методы обучения, отработка лексики и грамматики, аудирование, говорение, письмо, студенты колледжа.

\section{Abstract}

The article discusses the content of the integrated reading method in teaching English: the criteria for choosing texts, the types of accompanying exercises for practicing vocabulary, grammar 
and the use of various types of educational activity - reading, audience, writing and speaking. The article reflects the specifics of teaching college students to read-differences in the initial level of English language proficiency and the need for a differentiated approach to performing a set of exercises in integrated reading classes.

Keywords: the English language, integrated reading, interactive teaching methods, vocabulary and grammar development, listening, speaking, writing, college students.

Актуальность применения интегрированных методов в обучении английскому языку студентов колледжа обусловлена различием уровней языковой подготовки по иностранному языку учащихся, поступающих в колледж. Вариативность уровней успеваемости учащихся предопределяет расхождения в их владении грамматикой языка, навыками письменной и устной речи, распознавания языка на слух, но и применение неодинаковых учебнометодических комплексов и учебных программ создает у студентов различия в плане полноты их вокабуляра и его тематической сформированности.

Эти обстоятельства обусловливают необходимость интегрировать - свести к единой общей базе - имеющиеся у студентов знания в различных областях английского языка, чтобы эффективно выстраивать процесс их дальнейшего обучения.

Интегрированные методы обучения иностранным языкам, согласно коллективу авторов во главе с Р.А. Назимовой, опираются на применение комплексных упражнений, включающих в себя сразу несколько видов учебной активности: чтение, перевод, говорение, письмо, аудирование в различных форматах [5, с. 54]. За счет сочетания множественных видов учебной активности интегрированные методы обучения задействуют сразу несколько каналов восприятия студентов и благодаря этому погружают их в учебную ситуацию, приближенную к естественным ситуациям применения иностранного языка в реальности. Это обеспечивает ускоренное усвоение как новой лексики, так и грамматических конструкций, по причине высокой интенсивности тренировки способствуют быстрому выведению запоминаемых конструкций и лексических единиц в область оперативной памяти, в непосредственную доступность для повседневного применения лингвистических навыков.

По утверждению Л.Г.К. Мусаевой, интегрированные методы обучения часто базируются на интерактивных инструментах - групповой коммуникации, играх, веб-квестах, мультимедиа. Использование интерактива обеспечивает быструю и повышенную вовлеченность студентов в процесс занятия, создают условия для быстрой запоминаемости изучаемого материала [3, с. 96].

Интегрированное чтение как метод обучения английскому языку студентов колледжа предполагает создание комплекса разнонаправленных по сфере проработки языковых навыков учащихся упражнений [4, с. 36]. Часто интегрированному чтению выделяется отдельное занятие с домашним заданием, даваемым с целью закрепления освоенного на занятии материала. В качестве основы для упражнения выбирается аутентичный или адаптированный текст (в зависимости от уровня сложности оригинала), тематическая направленность которого соответствует тематической таксономии учебного курса. Текст может быть скорректирован или сокращен педагогом английского языка в зависимости от его субъективной оценки когнитивных потребностей конкретной учебной группы, но без ущерба для смысла и целостности восприятия текстового материала при чтении.

На основе подготовленного текста разрабатывается комплекс сопутствующих дидактических материалов и упражнений: вокабуляр предполагаемой новой лексики с еe переводом, а также ряд упражнения, нацеленных на:

1) проверку понимания прочитанного (в формате ответа на открытые вопросы, вопросы с выбором «true/false», вопросы с выбором варианта(ов) ответа из открытого перечня, задания на расстановку фраз или абзацев в правильном хронологическом или логическом порядке и др.); 
2) повторения и запоминание пройденной ранее и на текущем занятии лексики (устный или письменный перевод слов, фраз или отрывков текст, заполнение дополнительно составленных фраз (имеющих или не имеющих отношение к основному тексту) словами из нового вокабуляра, выполнение грамматических склонений новых лексических единиц в упражнениях грамматической направленности, заполнение и разыгрывание в парах диалогов с новой лексикой, свободное устное общение студентов по заданным вопросам или темам, имеющим коннотацию с новой лексикой и др.);

3) знакомство и закрепление в памяти учащихся новых грамматических конструкций и устойчивых выражений (упражнения на повторение различных фраз с новыми конструкциями, выполнение письменных упражнений на новые конструкции, самостоятельное составление свободных фраз с новыми конструкциями на заданную тематику и др.);

4) развитие аудиальных навыков учащихся (прослушивание записи базового текста с ответами на вопросы по содержанию в письменной или устной форме; прослушивание записи дополнительных текстов, диалогов, монологов, расшифровывающих изначальный текст либо развивающих его тематически, с выполнением сопутствующих заданий на понимание; прослушивание диалогической либо монологической речи одногруппников со вступлением в осмысленную коммуникацию по заданному речевому, грамматическому или лексическому шаблону).

В зависимости от тематической направленности и насыщенности базового текстового материала новыми для студентов элементами могут выбираться различные варианты дополнительных упражнений, однако при этом в комплекс важно включать хотя бы по одному упражнению на отработку каждого вида навыка (запоминание лексики, освоение грамматики, чтение, письмо, аудирование, говорение). Только за счет сочетания различных видов учебной активности занятия чтением приобретают интегрированную форму и дают синергетический эффект в плане ускоренного обучения студентов колледжа английскому языку.

По замечанию С.А. Корниловой, обучение студентов колледжа требует выработки некого усредненного по каждой группе подхода, учитывающего уровень знаний и навыков как наиболее успешных в основании английского языка учащихся, так и самых отстающих [1, с. 154]. Уровень новизны учебного материала устанавливается для среднего большинства учащихся на уровне не более $15 \%$ от всего содержания урока интегрированного чтения. При этом наиболее успешным большинство упражнений предлагается «на повторение» уже освоенного ими материала, а самые отстающие сталкиваются с повышенным содержанием нового материала и могут испытывать трудности с его освоением.

Такая ситуация требует от преподавателя дифференцированного подхода к мотивации студентов разного уровня. В отношении более «продвинутых» учащихся требуется популярное обоснование важности повторения знакомого им материала - для поддержания имеющихся знаний в активном виде. Ни в коем случае нельзя исключать «отличников» из общегрупповой активности - спрашивать их реже или давать меньше заданий, чем остальным. Это создает эффект отрешенности и рассеянности их внимания, резко снижает уровень мотивации к обучению и может привести к академическому отставанию в последующие периоды.

В отношении наиболее «слабых» учеников необходимо уделять больше времени отработке произношения новых для них слов и применению незнакомых грамматических конструкций. Также их уровень создает необходимость в дополнительных упражнениях и вопросах на понимание содержимого текста, чтобы устранить возможные пробелы в понимании происходящего на занятии. Также отстающим студентам могут потребоваться внеурочные консультации по пройденному материалу и дифференцированные по уровню 
сложности домашние задания (те же задания, что и основной группе плюс дополнительные более простые на отработку конструкций и лексики предыдущих уровней).

Тематическая направленность дидактических материалов для занятий интегрированного чтения, помимо отражения тематической таксономии учебного курса, должна затрагивать актуальные события и мейнстримные социальные течения, а также интересы возрастной группы студентов [2, с. 279]. Только при соблюдении этих условий возможно вызвать у учащихся моментальный интерес к теме занятия, простимулировать их творческий импульс к самовыражению по заданной теме и желание «разобраться» в ней. К числу таких тем в случае студентов колледжа могут относиться: молодежные эстрадные исполнители, молодежная мода, бренды, путешествия, города и достопримечательности, еда и напитки, профессиональная самореализация, самостоятельное творчество в области искусств и науки, история, катаклизмы, мистические явления, творчество различных писателей и др.

Таким образом, интегрированное чтение представляет собой эффективный в своей сути комплексный метод обучения английскому языку студентов колледжа. Он базируется на выборе интересующих учащихся текстовых материалов, которые преподносятся им через различные каналы восприятия информации, тренируя сразу совокупность языковых навыков. Занятия по чтению включают ряд сопутствующих упражнений, разрабатывающих лексические, грамматические знания, стимулирующих запоминание нового материала на уровне долго- и кратковременной памяти, вырабатывающих различные виды языковых компетенций - чтение, аудирование, говорение, письмо. За счет дифференцированного подхода к работе со студентами различного уровня владения языком грамотный преподаватель на уроках интегрированного чтения может не только способствовать эффективному приращению знаний всех учащихся группы, но и создать у них долговременную мотивацию к изучению английского языка в дальнейшем.

$$
* * *
$$

1. Корнилова С.А. Обучение чтению текстов на английском языке студентов колледжа с использованием материалов сайта brititshcouncil: из опыта работы / C.A, Корнилова // Crede Experto: транспорт, общество, образование, язык. - 2018. - № 3. - С. 153-165.

2. Лопатина А.И. Особенности обучения иностранному языку в системе среднего профессионального образования / А.И. Лопатина // Материалы научной и научно-методической конференции профессорскопреподавательского состава Кубанского государственного университета физической культуры, спорта и туризма. - 2018. - № 1. - С. 279-280.

3. Мусаева Л.Г.К. Возможности использования интерактивных методов в процессе укрепления новых знаний / Л.Г.К. Мусаева // Евразийская педагогическая конференция. Сборник статей IV Международной научнопрактической конференции. - 2019. - С. 95-97.

4. Щелокова И.Д. Применение метода «close reading» в интегрированном обучении английскому языку и литературе студентов вуза / И.Д. Щелокова, Т.В. Стапух // Вестник Оренбургского государственного университета. - 2017. - № 4 (204). - C. 33-38.

5. Nizamova R.A. Integrating language skills into the process of the english language teaching / R.A. Nizamova, H.A. Mamadalieva, B.H. Matkarimova // Вестник науки и образования. - 2019. - № 19-2 (73). - С. 53-55.

\section{Палецкая Т.В., Гайнуллина М.Э. \\ Организационно-педагогические условия обучения детей с нарушениями опорно- двигательного аппарата в инклюзивной практике}

ФГБОУ ВО «Новосибирский государственный педагогический университет» (Россия, Новосибирск)

doi: 10.18411/trnio-09-2021-58

\section{Аннотация}

Работа посвящена проблеме обучения детей с нарушениями опорно-двигательного аппарата в инклюзивной школе. Проведен анализ понятия организационно-педагогические 